\title{
The Properties of Gold Deposits Produced by DC, Pulse and Asymmetric AC Plating
}

\author{
J. W. Dini and H. R. Johnson
}

Sandia Laboratories, Livermore, CA., U.S.A.

In studies of the use of pulsed current (PC) or asymmetric AC in place of $D C$ in electrodeposition, considerable attention has been devoted to the effects of PC upon the widely applied hard gold coatings normally deposited by $D C$ from acid cyanide electrolytes containing cobalt or nickel. The authors of this article compare the properties of gold foils produced by $P C$, asymmetric $A C$ and $D C$ plating from a cyanidecitrate-sulphate electrolyte in the absence of alloying metals.

Sandia Laboratories have been engaged in a programme of comparisons of pulse plating, asymmetric $\mathrm{AC}$ plating and DC plating of gold on hybrid microcircuits (HMC's). This work, described in detail in an earlier report (1), concluded that for thicknesses of 3 and $6 \mu \mathrm{m}$, there was no noticeable effect of the deposition technique upon the porosities of deposits. This result was not surprising inasmuch as Rehrig (2) had previously shown that the improvement in porosity for $\mathrm{PC}$ plated deposits is significant only at thicknesses less than $1.0 \mu \mathrm{m}$.

Because of continued interest in the mechanical properties of electrodeposited gold, additional work has since been carried out to determine the influence of plating parameters on such properties and on the microstructure of coatings in both the as-deposited and heat treated conditions. PC, DC and asymmetric $\mathrm{AC}$ deposition modes were included in the investigational programme.
In its simplest form, pulse plating is carried out by interruption of DC during electrodeposition. The benefits of its use for plating gold have been extolled in recent literature ( 2 to 8 ), but most of the recorded work has been concerned with porosity and its reduction by pulse plating. Only two papers have dealt with properties of pulse plated deposits. Cheh (7) postulated that since an advantage of pulse plating is to raise the limiting current density, the technique might bring about an improvement in physical properties through structural modification of the electrodeposits. Lendvay and Raub (8) reported as-deposited tensile strengths 25 per cent higher and elongations 200 per cent higher for PC as compared with DC plated gold.

Asymmetric AC deposition is the superimposition of $\mathrm{AC}$ on $\mathrm{DC}$ with the peak voltage of the $\mathrm{AC}$ being larger than that of the DC voltage so that periodic reversal of polarity takes place. No published data are

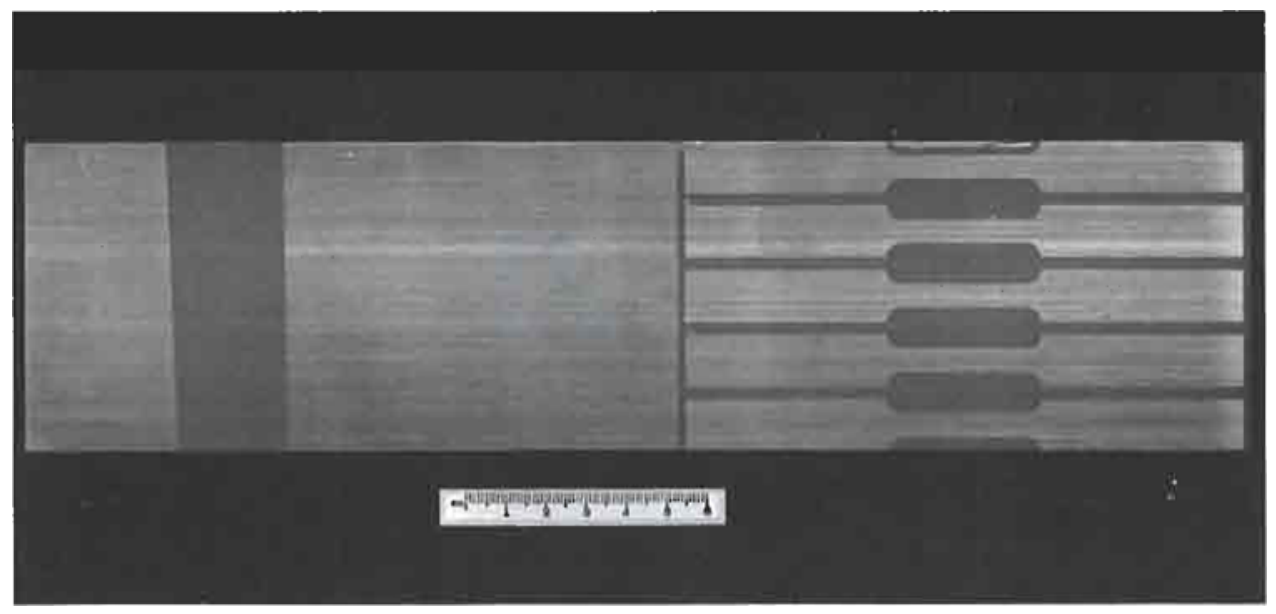

Fig. 1 The gold ioil tensile specimens used for this investigation were prepared by electrodeposition on an aluminium substrate in a pattern delineated by photoresist and by dissolntion of the substrate in caustic solution. The seale on this illustration is in centimetres 


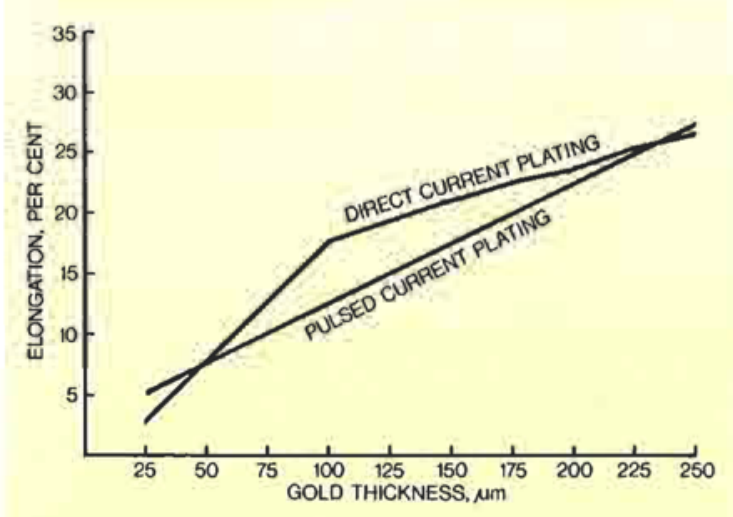

Fig. 2 Influence of the thickness of gold foils prepared by DC and PC plating from a citrate bath on their elongation as measured by tensile testing
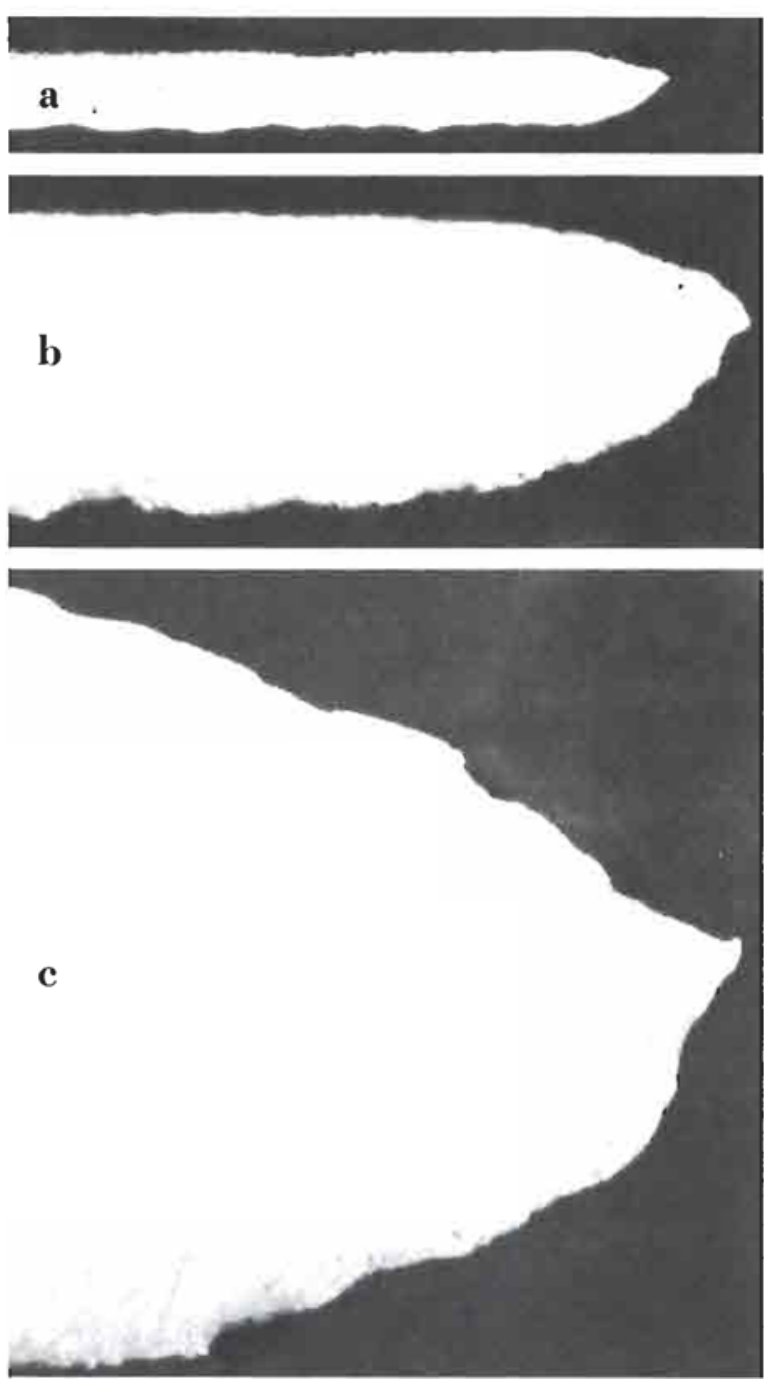

Fig. 3 Cross sections of electrodeposited yold foil tensile speciunens after testing to rupture. Elongations of 5, 11 and 23 per cent were recorded on samples a, b and $c$ which were 25,100 and $250 \mu$ m thick respectively. The pronounced necking exhibited by all three samples is characteristic of ductile behaviour

$\times 300$ available on the influence of this mode of deposition on the mechanical properties of gold.

\section{Experimental Details}

Gold tensile specimens $140 \mathrm{~mm}$ long and $13 \mathrm{~mm}$ wide with a reduced section of $38 \times 6.4 \mathrm{~mm}$ were produced with thicknesses ranging from 25 to $250 \mu \mathrm{m}$. Photoresist techniques were used to define the pattern of the specimens and five were prepared on an aluminium sheet during one plating cycle (Figure 1). The citrate solution described by Rehrig (2) was selected for this work. It contained $20 \mathrm{~g} / \mathrm{l}$ potassium gold cyanide, $75 \mathrm{~g} / 1$ ammonium citrate and $75 \mathrm{~g} / \mathrm{l} \mathrm{am}$ monium sulphate and was used at $60^{\circ} \mathrm{C}$ and $\mathrm{pH} 5.5$. DC plating was at a current density of $32.3 \mathrm{~A} / \mathrm{m}^{2}$, PC deposition was at the same average current density with a 9 per cent duty cycle $(0.9 \mathrm{~ms}$ on, $9 \mathrm{~ms}$ off $)$ and asymmetric $\mathrm{AC}$ deposition was at a current density of $32.3 \mathrm{~A} / \mathrm{m}^{2}$ with a 3 to 1 ratio of forward-toreverse current flow. After completion of plating and removal of the photoresist, the aluminium was dissolved in caustic solution. Mechanical properties were determined by testing on an Instron machine at a crosshead speed of $1.3 \mathrm{~mm} / \mathrm{minute}$. Some of the specimens were heated at $300^{\circ} \mathrm{C}$ for 2 hours prior to testing since these are conditions to which gold deposits would be subjected if used on HMC's (9). Optical microscopy and hardness measurements were used to further characterize the deposits.

\section{Mechanical Properties}

Increasing their thickness resulted in higher elongations for DC and PC plated deposits (Figure 2). This is in good agreement with the data of Dudderar and Koch (10), who have pointed out that for many electrodeposited foils elongation increases with thickness, a phenomenon attributed to a change in the necking behaviour, whereby the thinner foils undergo only localized strain at the region of smallest cross section. This situation can result in an overall elongation which gives a very poor indication of the foil's real ductility. A better evaluation of the extent of necking strain can be obtained from a metallographic cross section of a foil specimen after fracture. This is shown in Figure 3 which is a compilation of cross sections of deposits of thicknesses 25,100 and $250 \mu \mathrm{m}$ showing necking that occurred during tensile testing to rupture. The three foils exhibited elongations of 5 , 11 and 23 per cent respectively, but all clearly experienced more than 90 per cent reduction in area.

Deposits prepared by PC and DC plating exhibited a general decrease in ultimate tensile strength with increasing thickness (Figure 4). AC plated foils of only one thickness $(250 \mu \mathrm{m})$ were evaluated, so that no corresponding relationship was established for this deposition mode. 
Table I

Properties of As-Deposited and Heat Treated $250 \mu \mathrm{m}$ Thick Gold Foils Plated from a Citrate Bath

\begin{tabular}{|c|c|c|c|c|c|c|c|c|c|c|c|}
\hline \multirow{2}{*}{$\begin{array}{c}\text { Method } \\
\text { of } \\
\text { deposition }\end{array}$} & \multicolumn{3}{|c|}{$\begin{array}{l}\text { Yield strength*, } \\
\qquad \mathrm{MPa}^{*}\end{array}$} & \multicolumn{3}{|c|}{$\begin{array}{l}\text { Ultimate tensile } \\
\text { strength, } \mathrm{MPa}\end{array}$} & \multicolumn{3}{|c|}{$\begin{array}{l}\text { Elongation, } \\
\% \text { in } 25 \mathrm{~mm}\end{array}$} & \multicolumn{2}{|c|}{$\begin{array}{c}\text { Knoop hardness } \\
(25 \mathrm{~g})\end{array}$} \\
\hline & $\begin{array}{c}\text { as- } \\
\text { deposited }\end{array}$ & $\begin{array}{l}2 \mathrm{~h} \text { at } \\
300^{\circ} \mathrm{C}\end{array}$ & $\begin{array}{l}4 \mathrm{~h} \text { at } \\
300^{\circ} \mathrm{C}\end{array}$ & $\begin{array}{c}\text { as- } \\
\text { deposited }\end{array}$ & $\begin{array}{l}2 \mathrm{~h} \text { at } \\
300^{\circ} \mathrm{C}\end{array}$ & $\begin{array}{l}4 \mathrm{~h} \text { at } \\
300^{\circ} \mathrm{C}\end{array}$ & $\begin{array}{c}\text { as- } \\
\text { deposited }\end{array}$ & $\begin{array}{l}2 \mathrm{~h} \text { at } \\
300^{\circ} \mathrm{C}\end{array}$ & $\begin{array}{l}4 \mathrm{~h} \text { at } \\
300^{\circ} \mathrm{C}\end{array}$ & $\begin{array}{c}\text { as- } \\
\text { deposited }\end{array}$ & $\begin{array}{l}2 \mathrm{~h} \text { at } \\
300^{\circ} \mathrm{C}\end{array}$ \\
\hline DC & 60 & 59 & 52 & 141 & 126 & 123 & 26.3 & 29.1 & 30.2 & 69 & 68 \\
\hline$A C$ & 101 & 21 & 33 & 203 & 106 & 120 & 16.5 & 27.8 & 25.7 & 98 & 49 \\
\hline PC & 79 & 35 & 29 & 161 & 116 & 108 & 26.4 & 41.8 & 43.3 & 70 & 57 \\
\hline
\end{tabular}

Table I compares 0.2 per cent offset yield strength, ultimate tensile strength, hardness and elongation for $250 \mu \mathrm{m}$ thick foils produced by each of the three deposition modes. It also contains information on the influence of heating the deposits at $300^{\circ} \mathrm{C}$ for 2 and 4 hours prior to testing at room temperature. Inspection of this table reveals that:

(1) In the as-deposited condition, foils produced using asymmetric AC plating were stronger, harder and less ductile than those produced using DC or PC plating

(2) In the as-deposited condition PC plated foils were slightly stronger than DC plated foils but elongations were similar

(3) Heat treatment at $300^{\circ} \mathrm{C}$ for 2 hours reduced the yield, ultimate tensile strength and hardness of all deposits while it increased their elongation. Heating the deposits for an additional 2 hours at $300^{\circ} \mathrm{C}$ did not change these properties further.

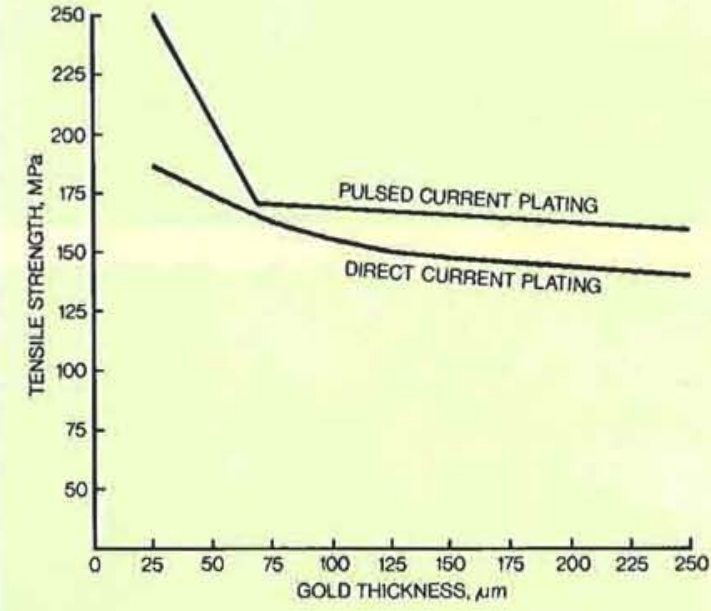

Fig. 4 Influence of the thickness of gold foils prepared by $\mathrm{DC}$ and $\mathrm{PC}$ plating from a citrate bath on their ultinate tensile strength
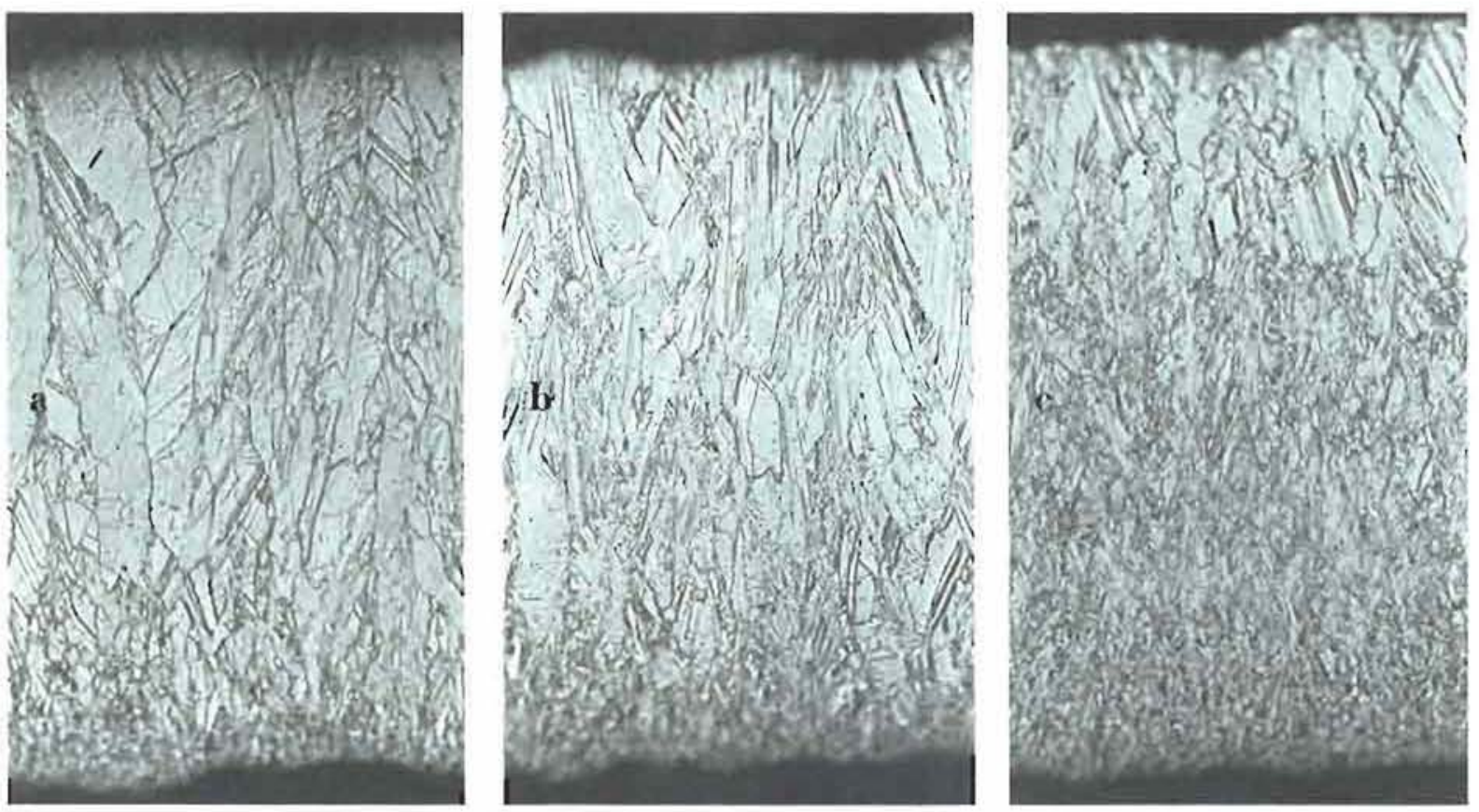

Fig. 5 Cross seetions of as-deposited gold foils prepared by (a) DC, (b) PC and (c) asymmetric AC plating from the same citrate bath 

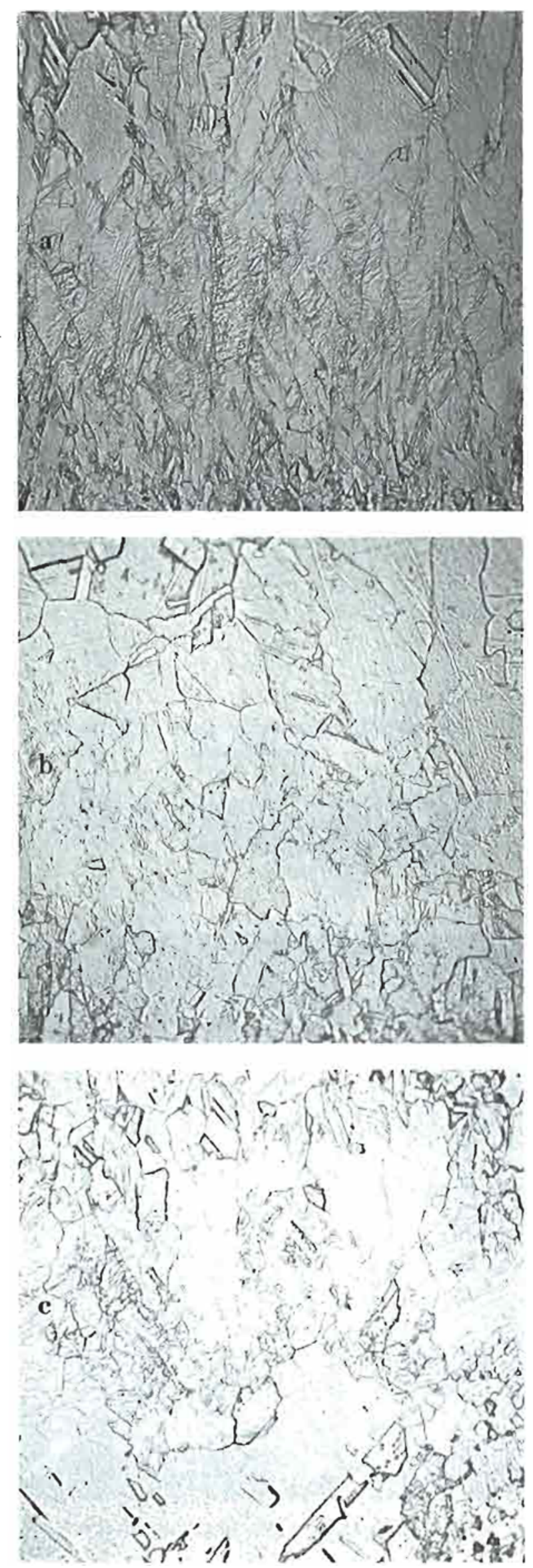

\section{Microstructure of the Deposits}

DC plating produced large columnar, coarsegrained deposits (Figure 5a). PC plated deposits (Figure 5b) were also coarse-grained, but the individual grains were narrower, more elongated and more uniform in size than those produced by DC. Use of asymmetric AC resulted in a much finer grain size (Figure 5c) and this is reflected in the approximately 50 per cent increase in tensile strength of these deposits when compared with DC deposits. All of the deposits exhibited large grains after they had been heated at $300^{\circ} \mathrm{C}$ (Figure 6).

\section{Summary}

In general, DC and PC plated gold deposits exhibit relatively similar properties. Increasing the thickness over the range of 25 to $250 \mu \mathrm{m}$ typically results in improved ductility and in a reduction in yield and ultimate tensile strength. Deposits $250 \mu \mathrm{m}$ thick produced by asymmetric AC are harder and less ductile than those produced by DC or PC plating. Heating the deposits at $300^{\circ}$ for both 2 and 4 hours causes a reduction in strength and an increase in elongation due to recrystallization and grain growth. Metallographic inspection reveals that deposits produced by DC or PC plating have coarser grains than those produced by asymmetric AC.

\section{Acknowledgements}

This work was supported by the U.S. Department of Energy under Contract Number AT-(29-1)789.

\section{References}

$1 \mathrm{~J}$. W. Dini and H. R. Johnson, in 'Proceedings of the 7th AES Plating in the Electronics Industry Symposium', American Electroplaters' Society, Winter Park, FL., 1979

2 D. L. Rehrig, Plating, 1974, 61, 43-46

3 A. J. Avila and M. J. Brown, Plating, 1970, 57, 1105-1108

4 D. L. Rehrig, H. Leidheiser, Jr. and M. R. Notis, Plating Surf. Finish., 1977, 64, (12), 40-44

5 A. M. Weisberg, H. Shoushanian and R. J. Morrissey, in 'Proceedings of the Design and Finishing of Printed Wiring and Hybrid Circuits Symposium', American Electroplaters' Sociery, Winter Park, FL., 1976

$6 \mathrm{H}$. Y. Cheh, P. C. Andricacos and H. B. Linford, Plating Surf. Finish., 1977, 64, (7), 42-44

7 H. Y. Cheh, Y. Electrochem. Soc., 1971, 118, 551-557

8 V. J. Lendway and Ch. J. Raub, Metalloberflachle, 1975, 29, (4), $165-167$

9 P. H. Holloway, Gold Bull., 1979, 12, (3), 99-106

10 T. D. Dudderar and F. B. Koch, in 'Properties of Electrodeposits, Their Measurements and Significance', The Electrochemical Society, Princeton, NJ., p. 187

Fig. 6 Cross sections of gold foils prepared by (a) DC, (b) $P C$ and $(c)$ asymmetric $A C$ plating from the same citrate bath and aged at $300^{\circ} \mathrm{C}$ for 2 hours. Comparison of these microstructures with those presented in Figure 5 shows that recrystallization and grain growth took place during the heal treaturent 